\title{
Reseña
}

\section{El declive de las democracias pactadas*}

\section{Por: Ángel Arellano**}

* Paola Bautista de Aleman El declive de las democracias pactadas. España, Chile y Venezuela. Caracas: Dahbar, 2021.

ISBN: 978-980-425-052-1

** Periodista. Doctor en Ciencias Sociales, Universidad de la República, Uruguay. Magíster en Estudios Políticos y de Gobierno, Universidad Metropolitana, Caracas. $\triangle$ asearellano@gmail.com https://orcid.org/0000-00025232-7369
¿Cómo se dan las crisis en el seno de las democracias pactadas? ¿Cuáles son las razones que empujan a los sistemas democráticos hacia un escenario de deterioro de las reglas formales e informales? ¿Qué posibilita la erosión de la democracia en aquellos sistemas políticos que gozaron de buen prestigio y salud?

El libro El declive de las democracias pactadas. España, Chile y Venezuela, de Paola Bautista de Aleman (2021), presenta tres casos de democracias que, décadas después de ser instaladas, entraron en crisis: Venezuela como caso de ruptura, con el quiebre de la dictadura militar de Marcos Pérez Jiménez, en 1958, y la posterior reinstalación de la democracia vigente hasta 1998, y dos casos de transición de la dictadura a la democracia: España con el fallecimiento de Francisco Franco, en 1975, y Chile con la salida del régimen pinochetista, entre 1988 y 1990.

Las tres experiencias descritas, aunque diferentes, coinciden en haber tenido regímenes democráticos anteriores a las dictaduras militares que los sucedieron: en Venezuela el trienio Adeco, liderado por Rómulo Betancourt (1945-1948), anterior a la dictadura de Pérez Jiménez; en España la Segunda República (1931-1939), previa al franquismo, y en Chile el gobierno de Salvador Allende (1970-1973), anterior a la dictadura de Augusto Pinochet.

El libro está organizado en cinco capítulos: el primero presenta una reflexión teórica sobre la democracia y el marco conceptual para abordar la temática; el segundo, el tercero y el cuarto desarrollan los casos de Venezuela, España y Chile respectivamente, y el quinto 
se dedica al análisis comparado y las conclusiones. El diseño metodológico es cualitativo-inductivo, basado en la comparación histórico-empírica de Nohlen (2010), que propone el análisis multicausal para establecer relaciones recíprocas, apoyado en el estudio del contexto histórico-político.

La autora habla de democracias pactadas a partir de la definición de Lijphart (1969) y su democracia consociacional, en la que la élite prodemocrática, constituida por todos los sectores políticos significativos, establece reglas a partir del consenso para hacer de la fragmentación política una democracia estable. Se apoya también en Godoy (1999) y su estudio del caso Chile, y en Romero (2010) y su revisión de la refundación democrática en Venezuela, quienes valorizan la disposición de las élites pactantes y del pacto en sí mismo como rasgo esencial de las democracias pactadas.

Por otro lado, para conceptualizar las crisis, la autora elaboró una definición propia atinente a las características de este trabajo; es un proceso constituido por tres niveles: 1) distanciamiento entre la sociedad y los valores democráticos establecidos en el pacto - constitucional- reinaugural de la democracia; 2) descalabro del sistema político, y 3) situaciones que afectan los cimientos del pacto político fundacional.

Bautista de Aleman comprueba que los elementos presentes en la crisis de democracias pactadas décadas después de su reinauguración están asociados con asuntos no resueltos durante la transición y que tienen que ver con: 1) actores que quedan fuera de los pactos de transición y cuya diversidad se materializa en la oferta política posterior —en tiempos de democracia-, en contextos proclives a la fragmentación, evidenciada en los tres casos, en los que partidos mayoritarios definieron la agenda de transición y acordaron las reglas de juego (pacto de Puntofijo en Venezuela, PSOE-PP en España, Concertación en Chile), y que más adelante, llegado el momento de crisis, experimentaron el surgimiento de nuevos actores fuera de sus órbitas de acción, y 2) actores ausentes durante los pactos de transición por no existir en ese momento - es decir, por falta de tiempo vital - que han reclamado su lugar en el sistema político a partir del uso de un discurso que esboza una reconstrucción inexacta de la transición e impulsa la polarización entre el ellos - partidos tradicionales - y el nosotros - nuevas fuerzas-, como el Movimiento Quinta República en Venezuela, Podemos y Vox en España, y el Frente Amplio en Chile (Bautista de Aleman, 2021, p. 306).

El libro indica que, en estos casos, a la reducción en la capacidad de representación en la transición se le sumaron dos variables contextuales: corrupción y bajo desempeño económico. Y estas variables revisten principal importancia en momentos de crisis, especialmente en la conexión entre la sociedad y el sistema político en términos de respaldo y veneración del acuerdo esencial, la Constitución. La obra expone un camino de diez tesis, insumo para la comprensión de estos procesos en particular y para la ciencia política comparada en particular: 
1) El aprendizaje prodemocrático en los actores se identifica siguiendo dos variables: la tradición política de cada país en cuanto al recuerdo de los momentos de conflicto y polarización de la etapa predictatorial - y su respectiva configuración y evolución institucional-, y el sufrimiento y el cambio político durante la dictadura y el proceso de transición.

2) La cristalización y la principalidad de los sectores moderados para convenir agendas democráticas comunes.

3) La unidad de la oposición democrática como factor clave para ganar las elecciones inaugurales de las democracias reinstaladas.

4) La confianza entre los actores políticos para acordar y pactar, variable construida por la moderación política y no por la cercanía o simpatía personal de los dirigentes - la dimensión humana de la élite política-.

5) La estabilidad como prioridad. Una vez reinstalado el régimen democrático, las constituciones y el marco jurídico de las dictaduras se mantuvieron, lo que respondió a una decisión política de los actores prodemocráticos para mantener las reglas del régimen autocrático y dar estabilidad a la transición como preámbulo a reformas posteriores: en Venezuela la Constitución de 1953 se mantuvo hasta 1961; en España las leyes fundamentales del franquismo fueron el antecedente de la Constitución de 1978, y en Chile la Constitución de 1980 —reformada en 2005- recién sería cambiada en 2021.

6) El reequilibrio del sistema democrático en momentos de crisis, a partir del reconocimiento de la transición democrática como un proceso incompleto que incluyó reformas - Venezuela y la reforma del Estado en los ochenta, España y la Ley para la Reforma Política en 1976, y Chile con las reformas a la Constitución en 2005- en el intento de solucionar tareas pendientes.

7) La identificación de un itinerario de desencanto democrático dividido en tres fases: desencanto político, desencanto con los partidos y desencanto sistémico o pérdida de fe en la democracia.

8) Las variables contextuales que juegan un papel esencial, los «problemas insolubles» de Linz (1989), son la corrupción y el bajo desempeño económico.

9) La fragmentación y la polarización en el sistema partidario son signo de erosión del sistema democrático.

10)El quiebre del sistema de democracia pactada es determinado por las decisiones que toma la élite política en sintonía con la sociedad.

El aprendizaje central del libro es la necesaria reflexión sobre el abordaje de las insatisfacciones de los actores - fundacionales y nuevos - para generar «reformas oportunas que den respuesta a las demandas sobrevenidas salvaguardando el orden constitucional» (Linz, 1989), y pone el acento en la actualización de los pactos que hacen 
a la democracia. En pocas palabras, reflexionar sobre la relación pacto-actualizaciónestabilidad democrática. Si bien el estudio de refiere al proceso de transición hacia y desde la dictadura militar, es un modelo que plantea preguntas y modelos para comprender y explicar la crisis de los sistemas democráticos como aporte para tener sociedades más reflexivas y partidos más resilientes y abiertos a las posibilidades de actualización y modernización de los pactos como uno de los antídotos en la lucha contra la polarización y la erosión de los códigos democráticos.

En la actualidad, las democracias en crisis son la norma, no la excepción. Las insatisfacciones de hoy, advertencias del ayer, fueron luces amarillas que no se sumaron a la hoja de ruta. ¿Se podía evitar la decadencia democrática de Venezuela si se hubieran actualizado los pactos de élites y abordado los descontentos sociales presentes en los ochenta y los noventa? ¿La democracia española habría ganado calidad con una actualización de sus regalas para no llegar a convertirse en una de las sociedades europeas más polarizadas en la actualidad? ¿Podía Chile haberse ahorrado el conflicto social de 2019 y 2020 con reformas oportunas desde la política? Son preguntas para pensar. En la política, al igual que en la vida común, hay resistencia al cambio. Cuando la modernidad y los nuevos tiempos tocan a la puerta, no falta quien mire para otro lado. Fue así durante la reforma del Estado en Venezuela, cuando, ante el reclamo de descentralización en los ochenta, los partidos proponentes al mismo tiempo se oponían, en un contexto de bajo rendimiento económico y escándalos de corrupción (Arellano, 2018). Un cóctel que, con una desprestigiada representatividad política, derivó en el ascenso de un régimen autoritario que desmanteló la institucionalidad y proscribió a la mayoría de los actores prodemocráticos. Venezuela es el caso más radical, el ejemplo más sintético de lo que ocurre cuando este camino planteado por Bautista de Aleman se cumple paso a paso y la crisis hace metástasis.

\section{Bibliografía}

Arellano, A. (2018). Posiciones refractarias ante el proceso de descentralización político-administrativa de Venezuela (1985-1988). En E. Mondolfi (ed.), Aproximaciones al siglo XX venezolano (pp. 214-234). Caracas: Universidad Metropolitana. Recuperado de https://www.unimet.edu.ve/unimetsite/wp-content/uploads/ 2018/02/Aproximaciones-al-Siglo-XX-Venezolano.pdf.

Godoy, A. (1999). Transición chilena a la democracia: pactada. Estudios Públicos, (74), 80-106. Recuperado de https://www.cepchile.cl/cep/estudios-publicos/n-61-ala-90/estudios-publicos-n-74/la-transicion-chilena-a-la-democracia-pactada.

Linz, J. (1989). La quiebra de las democracias. Madrid: Alianza. 
Lijphart, A. (1969). Consociational democracy. Cambridge: Cambridge University Press. Nohlen, D. (2010). Ciencia política y democracia en su contexto. Quito: Tribunal Contencioso Electoral.

Romero, A. (2010). La miseria del populismo: Historia y política de Venezuela. Caracas: Equinoccio. 